\title{
Temperature Effects on the Strength of Metal-Composite Multi-Bolted Joints
}

\section{CALIN-DUMITRU COMAN ${ }^{1}$}

\author{
${ }^{1}$ National Institute for Aerospace Research Elie Carafoli
}

May 5, 2020

\begin{abstract}
This paper presents the thermal effects on the damage initiation and growth in the CFRP (Carbon Fiber Reinforced Polymer) composite plate of the hybrid metal-composite multi-bolted joints. A fully 3D finite element model, incorporating all possible nonlinearities as geometric, in-plane lamina shear strains, lamina elastic properties reduction and friction-based contact is developed to anticipate the temperature gradient effects on the strength and failure modes of metal-composite multi-bolted joints. A PDA (Progressive Damage Analysis) material model which accounts for lamina nonlinear shear strains, Hashintype failure criteria and strain-based continuum degradation rules was developed using the UMAT user subroutine in Nastran (MSC. Software Inc.) commercial software. In order to validate the temperature effects on the failure modes of the joint with protruding and countersunk bolts, experiments were conducted using the SHM (Structural Health Monitoring) technique in the temperature controlled chamber. The results showed that the temperature effects on damage initiation and failure modes has to be taken into account in the design process in order to fructify the high specific strength of the composites. Experimental results were quite accurately predicted by the PDA material model, which proved to be computational efficient and can predict failure propagation and damage mechanism in hybrid metal-composite multi-bolted joints.
\end{abstract}

\section{Hosted file}

Main_Document (1).doc available at https://authorea.com/users/298839/articles/428160temperature-effects-on-the-strength-of-metal-composite-multi-bolted-joints 